Article

\title{
Semi-Automated Monitoring of a Mega-Scale Beach Nourishment Using High-Resolution TerraSAR-X Satellite Data
}

\author{
Elena Vandebroek ${ }^{1, *}$ (D), Roderik Lindenbergh ${ }^{2}$, Freek van Leijen ${ }^{2}$, Matthieu de Schipper ${ }^{3,4}$, \\ Sierd de Vries ${ }^{3}$ and Ramon Hanssen ${ }^{2}$ \\ 1 Department of Marine and Coastal Information Science, Deltares, 2629 HV Delft, The Netherlands \\ 2 Department of Geoscience and Remote Sensing, Delft University of Technology, 2628 CD Delft, \\ The Netherlands; r.c.lindenbergh@tudelft.nl (R.L.); F.J.vanLeijen@tudelft.nl (F.v.L.); \\ r.f.hanssen@tudelft.nl (R.H.) \\ 3 Department of Hydraulic Engineering, Delft University of Technology, 2628 CD Delft, The Netherlands; \\ M.A.deSchipper@tudelft.nl (M.d.S.); Sierd.deVries@tudelft.nl (S.d.V.) \\ 4 Shore Monitoring \& Research, 2583 DW The Hague, The Netherlands \\ * Correspondence: elena.vandebroek@gmail.com; Tel.: +31-628-088-097
}

Academic Editor: Richard Gloaguen

Received: 25 April 2017; Accepted: 23 June 2017; Published: 24 June 2017

\begin{abstract}
This paper presents a semi-automated approach to detecting coastal shoreline change with high spatial- and temporal-resolution using X-band synthetic aperture radar (SAR) data. The method was applied at the Sand Motor, a "mega-scale" beach nourishment project in the Netherlands. Natural processes, like waves, wind, and tides, gradually distribute the highly concentrated sand to adjacent beaches. Currently, various in-situ techniques are used to monitor the Sand Motor on a monthly basis. Meanwhile, the TerraSAR-X satellite collects two high-resolution $(3 \times 3 \mathrm{~m})$, cloud-penetrating SAR images every 11 days. This study investigates whether shorelines detected in TerraSAR-X imagery are accurate enough to monitor the shoreline dynamics of a project like the Sand Motor. The study proposes and implements a semi-automated workflow to extract shorelines from all 182 available TerraSAR-X images acquired between 2011 and 2014. The shorelines are validated using bi-monthly RTK-GPS topographic surveys and nearby wave and tide measurements. A valid shoreline could be extracted from $54 \%$ of the images. The horizontal accuracy of these shorelines is approximately $50 \mathrm{~m}$, which is sufficient to assess the larger scale shoreline dynamics of the Sand Motor. The accuracy is affected strongly by sea state and partly by acquisition geometry. We conclude that using frequent, high-resolution TerraSAR-X imagery is a valid option for assessing coastal dynamics on the order of tens of meters at approximately monthly intervals.
\end{abstract}

Keywords: high-resolution SAR imagery; TerraSAR-X; shoreline; beach nourishment; Sand Motor; coastal dynamics

\section{Introduction}

As climate change and coastal development increase the risks associated with coastal hazards, like erosion and flooding, coastal communities are taking steps to adapt and improve their resilience. The suite of tools to address coastal hazards is broadening. Conventional solutions, like seawalls, are increasingly being exchanged for more flexible and less environmentally detrimental solutions, such as beach nourishments. Unlike hard structural solutions, beach nourishments can be highly dynamic. One example of such a project, which is used as a case study in this paper, is the "Sand Motor," a mega-scale beach nourishment project on the Dutch coast (Section 2.1). In order to understand how beach nourishment projects like the Sand Motor are evolving and performing, frequent monitoring 
is necessary. Beach nourishments are usually monitored by surveying a set of topographic profiles from the back of the beach to the offshore and comparing them over time. However, remote sensing techniques have recently been gaining popularity, as in-situ techniques are labor-intensive, and the accuracy and availability of remotely sensed data are increasing [1].

Shoreline location and migration is a primary indicator for coastal erosion and is often used to evaluate safety against flooding [2]. The position of the shoreline can be determined using in-situ geographic positioning systems or remote sensing techniques [3]. Close range, airborne, and space-borne remote sensing techniques have all been used to detect shorelines [1]. Among the close-range techniques, video images from a high vantage point, such as the "Argus" monitoring system [4], provide near-continuous data of the interface between land and water. Camera stations have been erected at $\sim 40$ sites worldwide on towers or buildings (e.g., lighthouses, hotels) near the shoreline. A single station can monitor a region of $\sim 5 \mathrm{~km}$, obtaining a resolution of $\sim 0.2 \mathrm{~m}$ and $\sim 20 \mathrm{~m}$ in cross- and along-shore directions, respectively [4]. The high spatial and temporal resolution has made ARGUS a valuable data source for detailed investigation of coastal processes (e.g., [5-7]). However, for monitoring coastal systems on wider spatial scales and/or in developing countries, these systems are relatively costly and limited in coverage.

Aerial photography, on the other hand, can be obtained with small initial set up costs, [8-10]. Aerial photography has been employed for nearly a century, and the nearly perpendicular viewing angle makes rectifying and georeferencing the data easier than the aforementioned obliquely-sensed video imagery. Traditionally, aerial photographs are manually georeferenced and interpreted to digitize the shoreline. Modern image processing has made it possible to automate some of these processes [10]. While this approach can provide accurate and tide-controlled (i.e., collected at a certain tide level) shorelines, it is time consuming, requires user expertise, and is restricted in availability. More recently, airborne laser scanning has also been applied to monitor coastal dynamics [11-13] and delineate water areas [14]. When employed at low tide, airborne laser scanning allows for development of a high-resolution digital elevation model of the entire beach at the time of acquisition, from which shorelines can be derived. It is, however, an expensive technique. Therefore it is not feasible to monitor a coast at short (monthly) intervals, which is necessary for a system as dynamic in time as the Sand Motor.

Alternatively, satellite imagery is collected regularly over wider spatial scales. As the return energy is sampled at different wavelengths, including those that are favorable for distinguishing water [15], extracting shorelines from spectral satellite data is relatively easy and even possible at sub-pixel level [16]. Landsat missions, for example, have been collecting spectral satellite imagery for over forty years now, making it possible to assess coastal dynamics over decades $[17,18]$ and at a worldwide scale. The disadvantage of optical satellite imagery is that it is sensitive to cloud cover. When combined with an often-limited revisit time, this results in a temporal resolution on the order of months rather than weeks for locations that are frequently cloudy, which is the case for European coastal regions.

Synthetic aperture radar (SAR) is an active system operating at wavelengths that penetrate clouds, making it a continuous, all-weather system. The intensity of each pixel in an SAR image represents the proportion of microwave energy backscattered from the corresponding location on the ground. The number of satellite SAR missions is increasing, and some $5 \times 20 \mathrm{~m}$ resolution datasets are freely available, e.g., those acquired by the Sentinel-1 mission of the European Space Agency (ESA). Various authors have used SAR imagery to detect shorelines and flood limits along lakes, rivers, and coastlines [19-24]. Compared to other types of remotely sensed data, SAR images are useful for shoreline detection as they provide the strongest contrast between land and water [1], though wind and waves can reduce this contrast [21]. For the Dutch coast, where the average annual cloud cover is $67 \%$ [25], the ability of SAR to penetrate clouds and collect images independent of daylight conditions allows for a complete and systematic set of images. For example, Li et al., 2014 [22] used ERS and Envisat SAR images to create yearly topographic maps of the dynamic mudflat area in the 
north-west of Germany, using the so-called waterline method [26]. This method extracts waterlines from SAR images at different tide levels, converts them to geodetic heights using a hydrodynamic model, and creates a complete digital elevation model by interpolation [27].

In their effort to extract coastlines from SAR data, Kim et al. 2007 [28] report that shorter wavelength SAR (such as C- or X-band) is more successful at extracting the shoreline than longer wavelength SAR (L- and P-band). The polarization of the SAR signal also influences the performance of shoreline extraction. The Dutch Public Works Department [29] tested four different polarizations and found that the contrast between water and land was the greatest in HH-polarized (Horizontal transmit and Horizontal receive) images.

Among SAR missions, TerraSAR-X, operated by the German Aerospace Center (DLR), collects high-resolution X-band SAR data with a high revisit frequency (Section 2.2.1). This combination of high temporal and spatial resolution provides a high potential for studying dynamic coastal areas. Strozzi et al. 2012 [20] manually extracted shorelines from small glacial lakes sampled by TerraSAR-X data. In the present study, a semi-automated procedure is developed and applied to the Sand Motor study area (Section 2.1). Robinson et al. 2015 [30] already used six quad-polarization TerraSAR-X images to extract the shoreline at the same location as the current study, but this was done before the Sand Motor was constructed (before the shoreline dynamics were accelerated by the mega nourishment). Additionally, less validation data was available at that time.

This study proposes an efficient, semi-automated, and validated method to extract shorelines from a long time series of TerraSAR-X images to monitor the evolution of a large beach nourishment project. The method is applied to 182 images, which is, to the best of our knowledge, far more than analyzed in previous coastal studies. No manual selection took place; all images that exist for the study period are incorporated. Therefore, this study provides generic insights into what can be expected from TerraSAR-X images for shoreline detection along an exposed, dynamic coast. The TerraSAR-X dataset and additional auxiliary and validation data are described in Section 2.2. The shoreline extraction method is discussed in Section 2.3. The results, their validation, and their evaluation against different environmental parameters are described in Section 3.

\section{Materials and Methods}

\subsection{Study Area: The Sand Motor}

The west coast of the Netherlands has a slightly curved sandy shoreline that faces the North Sea basin (Figure 1). Although parts of the coast are reinforced with shore-normal rubble mound dams, the majority is unarmored [31]. The average tide range is $1.7 \mathrm{~m}$, and the mean significant wave height $\left(\mathrm{H}_{\mathrm{s}}\right)$ is $1.3 \mathrm{~m}$ [32]. The southern part of the Dutch coast, between Scheveningen and Hoek van Holland, has eroded over $300 \mathrm{~m}$ over the last three centuries. From the 1970s onward, regular artificial sand nourishments were implemented every 3-5 years to mitigate this coastal recession. Recently, with the projected increase in sea level rise and the more regional approach to coastal protection, large feeder or "mega-scale" nourishments were proposed [33]. A pilot project was executed in 2011, in which 21.5 million $\mathrm{m}^{3}$ of sand from $10 \mathrm{~km}$ offshore was placed along a $2.5 \mathrm{~km}$ stretch of coast, creating the so-called Sand Motor peninsula (Figure 2). The nourished sediment is intended to be redistributed by wind, waves, and currents, thus spreading sand to the narrower up- and down-coast beaches while gradually eroding the peninsula [34]. This mega-scale nourishment is expected to provide enough sand to protect the adjacent coastlines from coastal erosion and flooding for 20 years [33]. Due to the experimental and rapidly-evolving nature of the Sand Motor, an intensive monitoring program was established with frequent onshore and offshore surveys of the bed elevation (Section 2.2.2). These surveys show that over the timeframe of the current study, the peninsula eroded by approximately $300 \mathrm{~m}$, or $\sim 100 \mathrm{~m} /$ year, and the sand spread alongshore over a length of approximately $4 \mathrm{~km}$ [34]. This evolution is shown clearly in Figure 2. 
The in-situ topographic surveys are, however, expensive and time-consuming. Similar projects to the Sand Motor are currently implemented at other locations in the Netherlands and abroad. These mega-nourishment projects call for new, more affordable, and feasible measurement approaches.

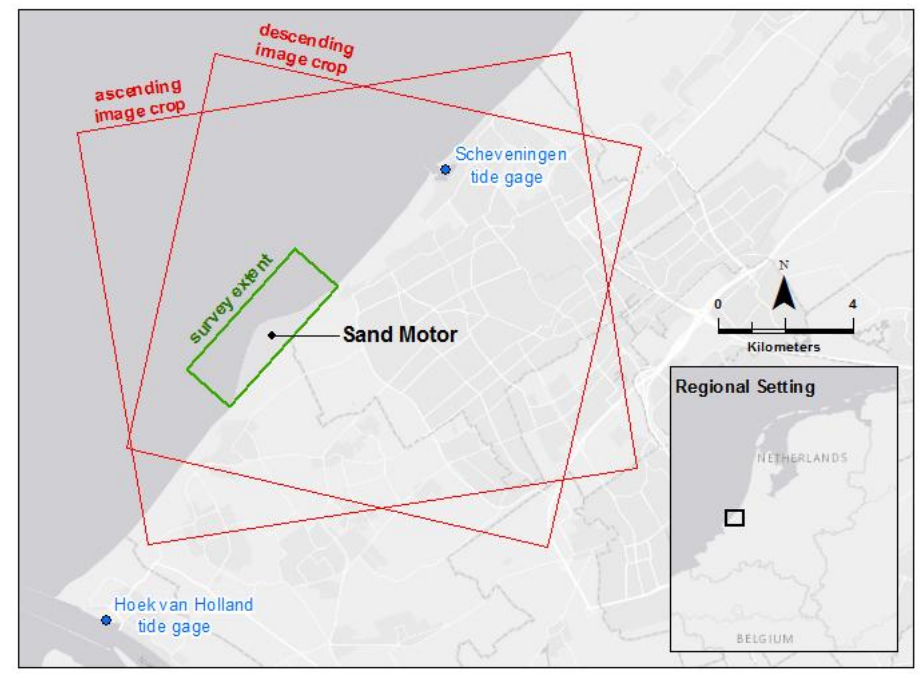

Figure 1. Map of the study area, including the Sand Motor and the adjacent Dutch shoreline. The extent of analysis of the TerraSAR-X images, from both the ascending and descending satellite orbits, are shown in red. The extent of the monitoring surveys used to validate the shoreline detection is shown in green. The Hoek van Holland and Scheveningen tide gauges were both used to estimate the water level at the Sand Motor.

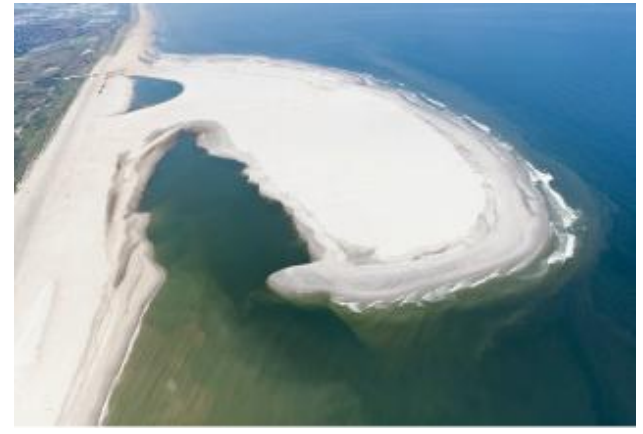

(a)

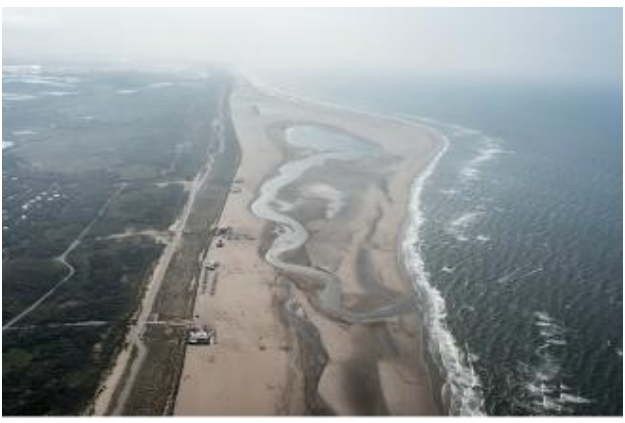

(b)

Figure 2. Aerial photographs of the Sand Motor pilot project in (a) July 2011 and (b) September 2014. Photos by Joop van Houdt/Ministry of Public Works and the Environment.

\subsection{Input Data}

This section describes each of the datasets used in this study, providing reported accuracy, resolution, and additional metadata, as relevant. Sections 2.3 and 3 describe in further detail how these datasets were used in the analysis. The TerraSAR-X satellite images, from which shorelines are derived, are described first. Second, topographic survey data, which was used to validate the shorelines extracted from the satellite images, is introduced. The third section describes environmental conditions such as water levels and waves, which were used to analyze the horizontal location accuracy of the shoreline detections.

\subsubsection{TerraSAR-X Satellite Images}

This study uses data collected by TerraSAR-X, a German earth-observation satellite mission, starting in June 2007. Since the satellite generally only acquires data based on user request, and we 
intended to analyze a long time series, we use existing datasets in StripMap mode. The advantage of StripMap mode is that relatively large areas are covered $(30 \times 50 \mathrm{~km}$ per image) at high ground resolution $(3 \times 3 \mathrm{~m})$. Imagery at even higher resolution (SpotLight mode) can be acquired, though the spatial coverage is much more limited. However, no SpotLight data stacks exist for the area of interest. For the same reason, imagery in $\mathrm{HH}$ polarization is used. We based our analysis on data in Single-Look Complex (SLC) format, readily available to the authors because of an ongoing project with the German Aerospace Center (DLR) on surface motion by radar interferometry. A total of 182 images were available from April 2011, before the Sand Motor was constructed, through September 2014. TerraSAR-X has a repeat cycle of 11 days. Within this period, both an image from the ascending and the descending orbit is acquired. The 79 ascending and 103 descending available images used in this study were always collected at the same time of day: 17:27 UTC and 06:08 UTC, respectively. The SAR signal is transmitted under an angle with respect to the nadir, resulting in incidence angles on the surface of approximately $39^{\circ}$ and $24^{\circ}$ for the ascending and descending images, respectively. The SAR incidence angle is defined as the angle between the incident radar beam and the normal of the illuminated surface. Radiometric calibration of the SAR data was not required for this study, since intercomparison of the radar images in the data stacks is not needed, and the calibration would not affect the detectability of the shoreline.

\subsubsection{Topographic Surveys}

The evolution of the Sand Motor has been monitored closely through high-resolution RTK-GPS topographic and bathymetric surveys since construction was completed [34]. These surveys were conducted monthly from August 2011 through August 2012 and subsequently every two months (total of 27 surveys). The 124 cross-shore transects cover an extent of $4.6 \mathrm{~km}$ alongshore and $1.8 \mathrm{~km}$ cross-shore, fully encompassing the Sand Motor (Figure 1). The vertical accuracy of the surveys near the shoreline is approximately $5 \mathrm{~cm}$ [34].

\subsubsection{Environmental Conditions}

Environmental conditions were used to interpret the accuracy of the shorelines detected in the satellite imagery. First, water levels were estimated at the moment each satellite image was collected in order to identify the corresponding location of the shoreline in the topographic surveys (Section 3.2). The water levels were obtained from two tide gauges at approximately equal distances from the Sand Motor. The Scheveningen gauge is located approximately $5 \mathrm{~km}$ northeast of the Sand Motor, while the Hoek van Holland gauge lies $7.5 \mathrm{~km}$ southwest (Figure 1). The tidal signals measured at the two gauges are shifted by approximately $15 \mathrm{~min}$, but have nearly the same shape. The two signals were combined to estimate the water level at the Sand Motor.

Meteorological data was obtained from the Royal Netherlands Meteorological Institute (KNMI), which maintains a large network of weather stations throughout the Netherlands. The nearest station to the Sand Motor site, approximately $7 \mathrm{~km}$ southwest, is at Hoek van Holland. Daily average wind speed, average temperature, and precipitation totals were obtained. Wave properties were obtained from the Maasmond wave gauge, which is located approximately $12 \mathrm{~km}$ southwest of the Sand Motor. Hourly $\mathrm{H}_{\mathrm{s}}$ and mean wave periods $\left(\mathrm{T}_{\mathrm{m}}\right)$ were available for the duration of this study.

\subsection{Methods}

A semi-automated 4-step method was developed that extracts the shoreline from a series of images without substantial user input (Figure 3), making it feasible to process the 182 SAR images. The method relies on a difference in intensity between the water and land to extract the shoreline. First, some pre-processing steps are taken to prepare the images for analysis. Next, k-means clustering is used to classify image pixels into water or land. The shoreline is then extracted using a region-growing algorithm. Finally, the shoreline is georeferenced. 
The term "shoreline," is used throughout this paper to represent the instantaneous intersection of water and land, and should not be confused with existing definitions associated with the term. Shorelines are sometimes defined as a certain water level (e.g., the mean high water line) or other feature on the beach. In this context, the shoreline is simply the intersection of water and land at any given time, and has no tidal definition. Since the tide level is different in each SAR image, the shorelines derived from the SAR images cannot be directly compared. A shoreline detected at high tide could be $500 \mathrm{~m}$ inland of a shoreline detected at low tide. Future studies should investigate the best methods for correcting these shorelines to a common vertical datum so they can be compared more easily, improving coastal monitoring.

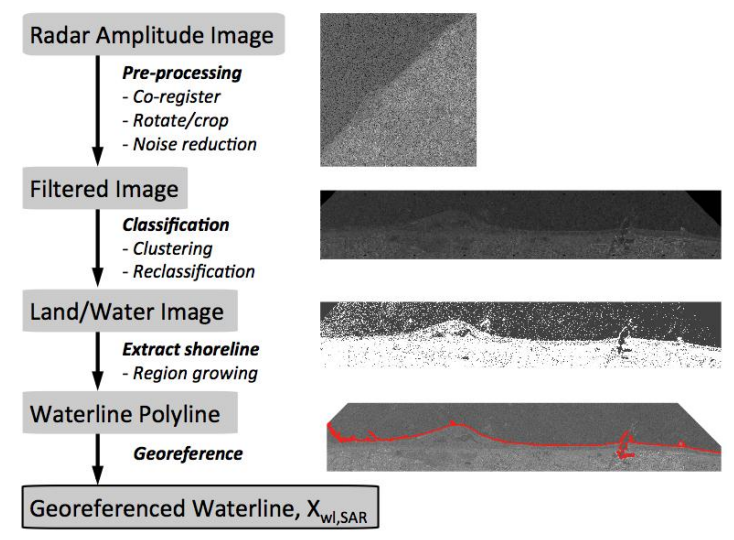

Figure 3. General workflow to process synthetic aperture radar (SAR) imagery and extract shoreline. Four main steps can be distinguished: (1) pre-processing, (2) image classification, (3) shoreline extraction, and (4) georeferencing.

\subsubsection{Pre-Processing SAR Images}

The first step in the analysis is the sub-pixel level alignment of the Single-Look Complex (SLC) satellite SAR images with respect to a reference image, separately for the ascending and descending datasets. The ascending and descending images are processed separately because they have different orientations (see Figure 1). Aligning the two sets of images with each other would require projecting both sets of images into a new coordinate system, which would be computationally intense for such large raster images. Instead, the two sets of images are processed separately, up to the point where the shoreline has been extracted. Then the shoreline data, which is vector data and therefore much smaller in size, is projected (georeferenced) into real-world coordinates. See Section 2.3.4 for a description of this georeferencing step. The objective of this approach is to ensure an internal consistency within the datasets, since only a single set of georeferencing parameters is required.

During the co-registration process, the images are first cropped to an extent that covers the Sand Motor and adjacent beaches, as indicated in Figure 1, to reduce processing time for the other pre-processing steps. The co-registration of the SAR images, which ensures that the descending (or ascending) images align with themselves, is then performed using the open-source software DORIS (Delft Object-Oriented Radar Interferometric Software) [35]. The software is typically used for SAR interferometric applications, requiring high accuracy during the co-registration. Using a windows-based image matching approach, together with a robust scheme of outlier testing, accuracies of 0.1 pixel are obtained [36]. Hence, for the $3 \times 3 \mathrm{~m}$ StripMap data, a relative positioning accuracy of $30 \mathrm{~cm}$ can be assumed between the reference image and the other images.

To reduce the subsequent processing times, the co-registered images are then rotated by $-45^{\circ}$, resampled, and cropped to include only a narrow rectangle $(23 \times 2 \mathrm{~km})$ along the shoreline. To reduce the noise level in the radar backscatter, a low pass Wiener filter $(3 \times 3$ cell, the smallest possible to 
maintain a high-resolution) is applied to the images. Adaptive Wiener filters perform better than conventional mean or median filters in removing typical SAR speckle noise [37,38].

\subsubsection{Classification: Distinguishing between Land and Water Pixels}

The co-registered images are classified into land and water using a two-step semi-automated process: through clustering and reclassification. First proposed over 50 years ago, K-means clustering is one of the most popular algorithms for clustering due to its ease of use, efficiency, and success [39]. $\mathrm{K}$-means clustering is applied to each individual image and creates seven unique pixel clusters. K-means uses an iterative algorithm to develop distinct clusters by minimizing the sum of the distances of pixels to their cluster mean [40]. Pixels are moved between clusters until this distance is minimized. The number of clusters is set manually by testing a range of numbers and selecting the number that produced the clearest distinction between land and water. This number was then kept constant for all images. Reducing or increasing the number of clusters by 2 or 3 does not substantially change the results. Next, the seven clusters are classified into two classes (land and water) using three user-defined training regions located in the water, on land, and on the beach (example in Figure 4). Due to the slightly different orientations of the ascending and descending images, two different sets of training regions were chosen for the two image orientations. If a specified cluster occurred more often in the land or beach than in the water, it was assigned to the land class. Remaining clusters were reclassified as water.

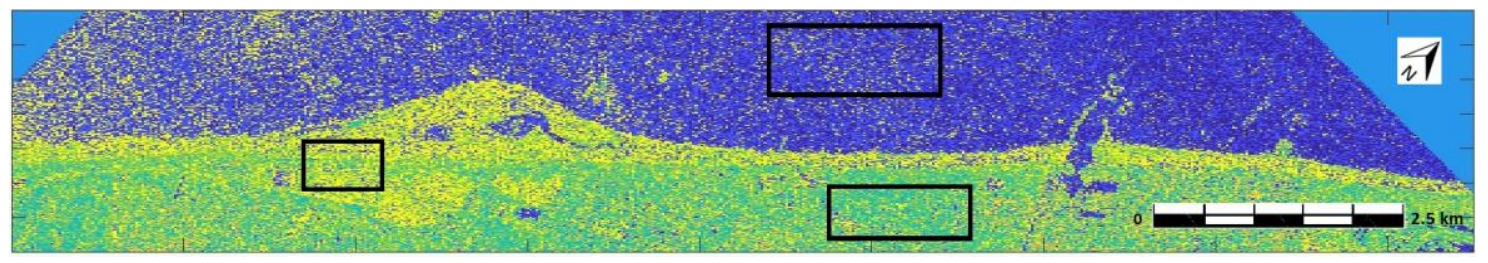

Figure 4. Three user-defined training regions (black rectangles) for the ascending SAR images depicted over the 7-cluster image resulting from K-means clustering. The training regions were used to assign each of the seven clusters to either the land or the water class.

\subsubsection{Shoreline Extraction from Classified Image}

A "region growing" approach is used to detect the shoreline in the classified image. Region growing is an image segmentation method that begins at a seed pixel and incrementally determines whether neighboring pixels should be added to the region. For this project, the algorithm searches for adjacent land pixels starting at a seed pixel on land. The seed pixel was set at a fixed coordinate in all the SAR images, in an area inland of the beach. If that pixel happened to be classified as water, the nearest land pixel to the left became the seed pixel. The land region grows as long as other land pixels touch the growing land region. Once the contiguous land region is identified, a polyline is drawn around the perimeter. As can be seen in Figure 2, the Sand Motor contains a small lake and a tidal lagoon, both of which result in additional shorelines. The region growing approach aims to detect the most seaward interface between the North Sea and the sandy beach. The seed pixel could also be selected in the offshore water area. This was tested and did not result in significantly different shoreline detections.

\subsubsection{Shoreline Georeferencing}

A transformation was developed to convert the extracted shorelines from image coordinates to real world coordinates. This allows them to be compared with survey data. A georeferenced aerial photo with 1-meter resolution, obtained from the Netherlands Geospatial Data Service Center, was used to identify control points for georeferencing. The image was collected in the summer of 2006 and has a reported root mean square positioning accuracy of $25 \mathrm{~cm}$. Using this air photo, 21 well-distributed 
control points were selected that could be identified in both the SAR image and the aerial photo. Based on these control points, a projective transformation is estimated. Projective transformations can handle changes caused by tilt of the image plane relative to the object plane, such as imagery taken from a satellite [41]. The root mean square errors at the control points of the projective transformation for the ascending and descending images were $10.6 \mathrm{~m}$ and $11.3 \mathrm{~m}$, respectively. The projective transformation was then applied to all shorelines extracted from the SAR images.

\subsubsection{Validation Using In-Situ Data}

The shoreline detections were validated using shoreline locations derived from morphological data and measured water levels. Since the water level during satellite image acquisition depends on the tide and surge, it is necessary to take this variation into account during validation. We assume that the shoreline detected in the SAR images corresponds to the still water level, which is measured by two nearby tide gauges (Section 2.2.3). Note that the still water level is the average water surface elevation at any time, which includes tide level, storm surge, and other long-period variations. It does not include variations due to waves or wave set-up. The water level corresponding to each SAR image was interpolated from the still water level time series using the exact date and time of image collection. Each SAR image was paired with the topographic survey that was done closest in time to the SAR image collection (95\% of the SAR images were collected within 36 days of a topographic survey). The location of the shoreline, as measured by the surveys, is derived as the intersection between each of the 124 measured cross-shore profiles and the water level at the time of satellite passage (Figure 5). This set of 124 shoreline locations derived from in-situ data ( $\left.\mathrm{X}_{\mathrm{WL}, \mathrm{IS}}\right)$ is compared with the SAR-detected shoreline locations $\left(\mathrm{X}_{\mathrm{WL}, \mathrm{SAR}}\right)$, thus providing an estimate of the horizontal error in shoreline position (Figure 5).

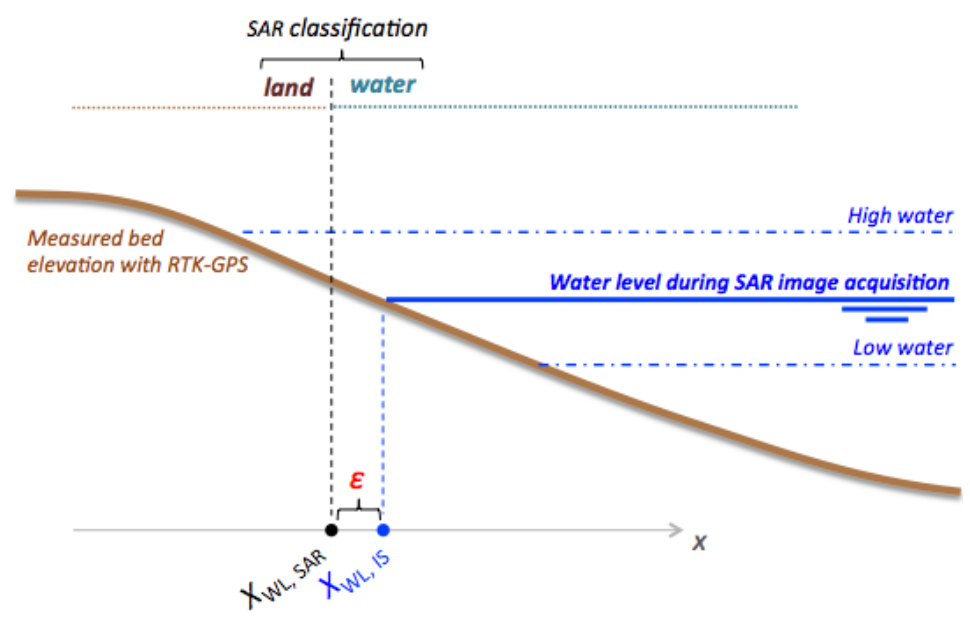

Figure 5. Derivation of in-situ shoreline $\left(X_{\mathrm{WL}, \mathrm{IS}}\right)$ and comparison with SAR-derived shorelines $\left(\mathrm{X}_{\mathrm{WL}, \mathrm{SAR}}\right)$ to estimate error, $\varepsilon$.

It should be noted that some uncertainty exists in this procedure since the shoreline location will also be influenced by local setup by wind and waves. Local wind and wave setup can be in the order of $0.5 \mathrm{~m}$ [42]. For a beach slope of 1:50, which is representative for the study area, this translates into a deviation of $25 \mathrm{~m}$ in shoreline location.

\section{Results}

\subsection{Qualitative Inspection of TerraSAR-X Derived Shorelines}

Initially, the performance of the shoreline detections was visually inspected. Figure 6 presents one example of a successful shoreline detection and three examples with poor quality. The shoreline 
detection is categorized into three categories (Table 1): (i) Good, (ii) Acceptable, and (iii) Poor or defect image. The criteria for a Good, or successful, detection are that the derived shoreline does not contain large spatial discontinuities and is close to the previously derived coastline. An Acceptable shoreline is one that generally follows the waterline but has some anomalies, especially in the vicinity of the Sand Motor. Defect images either did not result in any shoreline detection or showed broad swaths of light across the entire image. In the current study these criteria are examined visually, but these steps could be automated in the future. Table 1 summarizes the number of shorelines in each class, and the frequency of occurrence in ascending and descending images.

Table 1. Summary of visual categorization of shoreline detection quality for ascending and descending images.

\begin{tabular}{ccccccc}
\hline \multirow{2}{*}{ Shoreline Detection Quality } & \multicolumn{2}{c}{ Ascending } & \multicolumn{2}{c}{ Descending } & \multicolumn{2}{c}{ Total } \\
\cline { 2 - 7 } & $\#$ & $\mathbf{\%}$ & $\#$ & $\%$ & $\#$ & $\%$ \\
\hline Good & 42 & $53 \%$ & 30 & $29 \%$ & 72 & $40 \%$ \\
Acceptable & 20 & $25 \%$ & 8 & $8 \%$ & 28 & $15 \%$ \\
Poor or defect image & 17 & $22 \%$ & 65 & $63 \%$ & 82 & $45 \%$ \\
Total & $\mathbf{7 9}$ & $\mathbf{1 0 0} \%$ & $\mathbf{1 0 3}$ & $\mathbf{1 0 0} \%$ & $\mathbf{1 8 2}$ & $\mathbf{1 0 0} \%$ \\
\hline
\end{tabular}
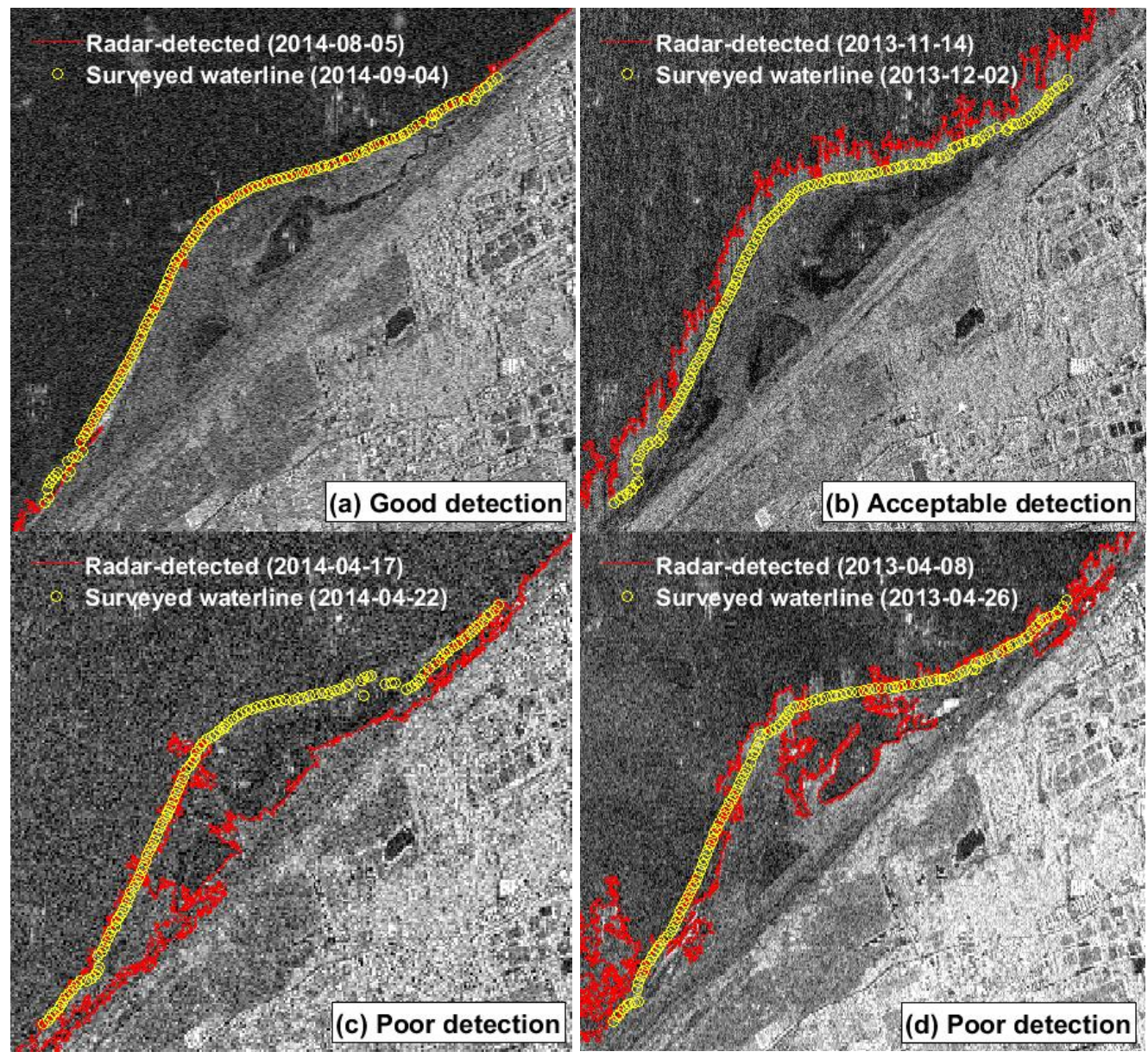

Figure 6. (a) Example of a good SAR shoreline detection. (b) Example of an acceptable detection. During high wave conditions $\left(\mathrm{H}_{\mathrm{s}}=2.4 \mathrm{~m}\right.$ at Maasmond), the interface between land and water becomes noisy and shifts offshore, likely due to a wider surf zone. Two examples of poor detections: (c) The contrast between the Sand Motor and water is too low, resulting in the Sand Motor not being captured in the shoreline. (d) Dark areas within the Sand Motor and light areas offshore result in poor detection of the shoreline. Potential reasons for the differences in contrast are discussed in Sections 3.3 and 3.4 . 


\subsection{Horizontal Error of Shoreline Estimates}

The TerraSAR-X data from July 2011 through September 2014 are quantitatively compared with 27 in-situ topographic surveys. A time sequence of derived shorelines is shown in Figures 7 and 8 for both methods. The SAR shoreline is sometimes quite noisy (Figure 6). This often results in multiple intersections between the topographic transect and the SAR shoreline. As discussed in Section 2.3.5, the horizontal error in the shoreline position, $\varepsilon$, was calculated for each transect as the distance between the surveyed shoreline location and the SAR-detected shoreline location(s). Next, the median error of all 124 transects is calculated to provide a relative error estimate for one SAR image. In summary, this validation method calculates the median distance between the SAR-derived shoreline and the survey-derived shoreline at 124 locations, evenly spaced alongshore. Results for the error values in the three categories are given in Table 2. Only images for which at least $95 \%$ of transects intersected both the survey- and SAR-derived shoreline were included (excluding 30 images; see footnote in Table 2).

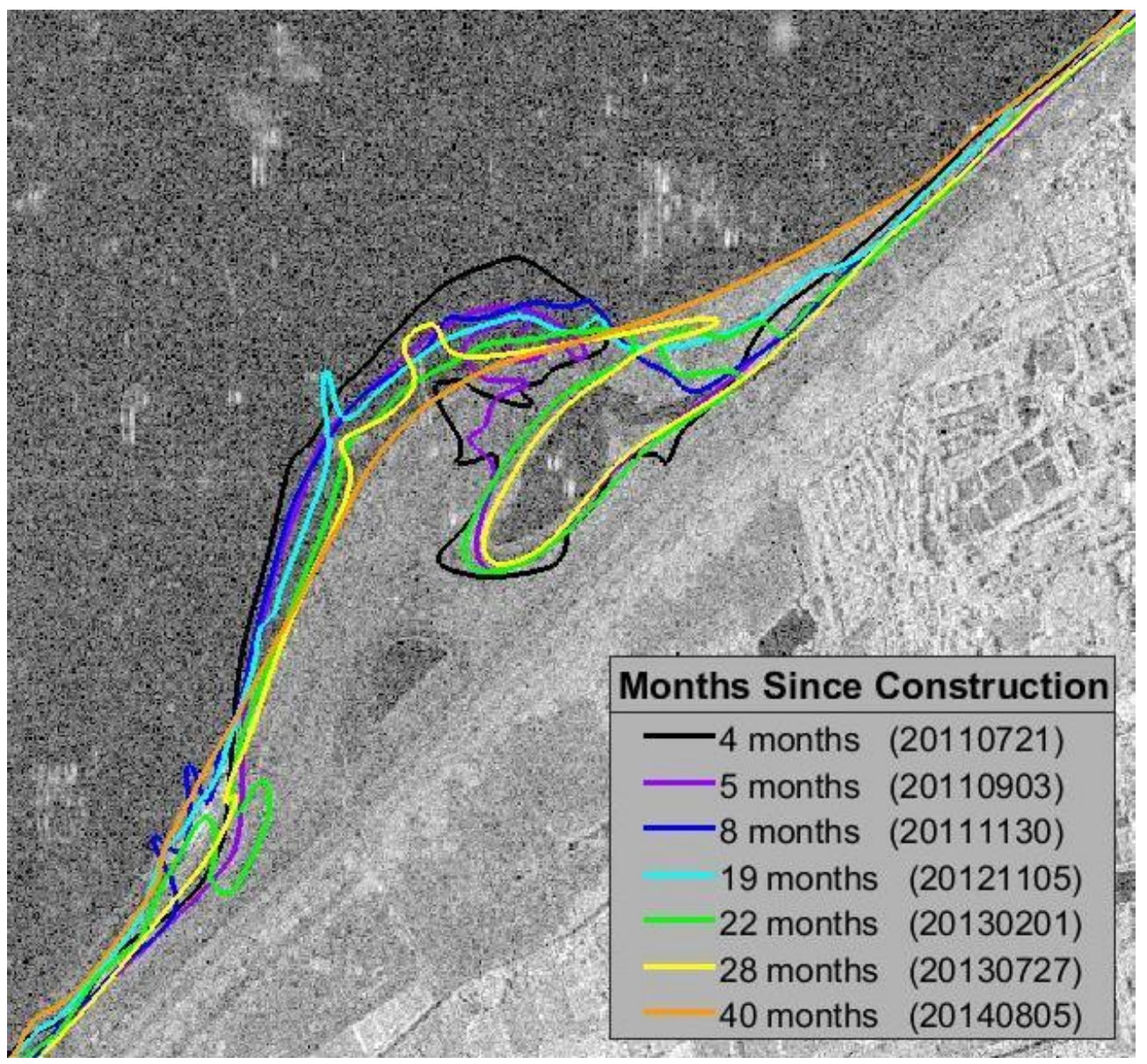

Figure 7. Example time series of good SAR shorelines. These example shorelines were derived from images collected during a tide of 100 to $150 \mathrm{~cm}$ NAP (Amsterdam Ordnance Datum). The shorelines were smoothed using a moving average filter. Background image corresponds to 40 months. 


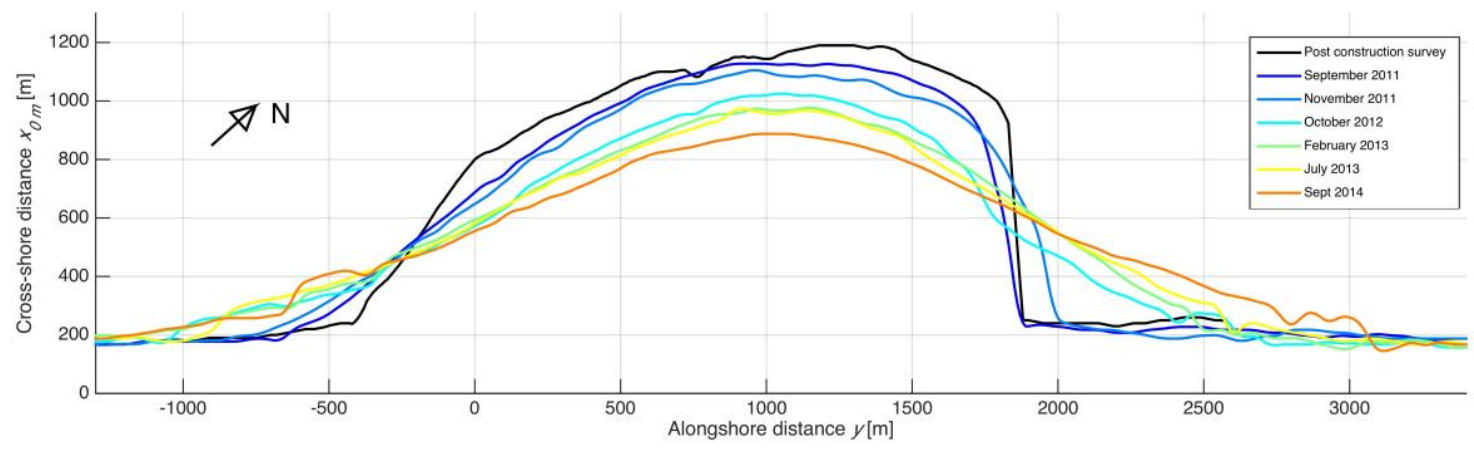

Figure 8. Shorelines derived from RTK-GPS surveys for dates corresponding to those of the SAR shorelines in Figure 7. Alongshore distance in [m].

Table 2. Summary horizontal errors on the derived shorelines using the in-situ surveys.

\begin{tabular}{cccc}
\hline \multirow{2}{*}{ Visual Classification Categories } & \multicolumn{3}{c}{ Median Horizontal Error $\boldsymbol{\varepsilon}$, Meters (\# Images) ${ }^{\mathbf{1}}$} \\
\cline { 2 - 4 } & Ascending Images & Descending Images & Ascending and Descending Images \\
\hline A. Good & $53.9(39)$ & $36.3(21)$ & $43.7(60)$ \\
B. Acceptable & $112.4(16)$ & $48.9(7)$ & $81.9(23)$ \\
A + B. Good or Acceptable & $58.8(55)$ & $40.1(28)$ & $\mathbf{5 1 . 2 ( 8 3 )}$ \\
C. Poor & $354.4(12)$ & $282.8(14)$ & $297.6(26)$ \\
\hline
\end{tabular}

${ }^{1}$ A total of 17 images ( 9 ascending and 8 descending) collected from April through June 2011 were excluded from this error analysis because topographic surveys were not available before July 2011. A total of 26 images were excluded because they were defective. Finally, 30 images (4 Good, 1 Acceptable, and 25 Poor) were excluded because the detected shoreline did not intersect $95 \%$ of the cross-shore transects.

\subsection{Ascending versus Descending Image Results}

The proposed method of extracting shorelines from SAR images shows a dependency on the acquisition characteristics, as shoreline extraction proved more successful in the ascending images than in the descending images. While 53\% of the ascending images were "Good," only $29 \%$ of the descending images fell into these categories (Table 1). Upon further examination, the descending images show less contrast between the land and water areas. This was tested by identifying a square region in both the land and water areas, calculating the average intensity in these two regions for each image, and then calculating the "intensity ratio" (ratio of the land intensity to the ocean intensity). Figure 9 shows the intensity ratio for both the ascending and descending images versus wave height. The average intensity ratio for ascending images was 1.31, while that of descending images was 1.08 (Figure 9). An intensity ratio of 1 would mean that the land and water areas have, on average, the same intensity, making them difficult to distinguish from each other. This likely explains why the ascending detections had a higher rate of success. This difference in intensity ratio is likely caused by a difference in incidence angle: the ascending images have an incidence angle of $39^{\circ}$, while the descending images have an incidence angle of $24^{\circ}$. The low angle of the descending images leads to a stronger backscatter, since part of the specular reflection is still received at the SAR antenna. For large incidence angles, most signal power is reflected away from the satellite, causing low backscatter intensity at sea surfaces [43]. Since both the ascending and descending acquisitions are acquired in $\mathrm{HH}$ polarization mode, the polarization is not a factor in the difference in intensity. In general, $\mathrm{HH}$ polarization results in lower backscatter at sea surfaces compared to VV polarization [29,43]. Hence, the best performance of our methodology is expected for SAR images acquired with $\mathrm{HH}$ polarization and a large incidence angle. Because fewer of the descending images have good detections, the subsequent error analysis and comparison with environmental parameters were only conducted for the ascending image dataset. 


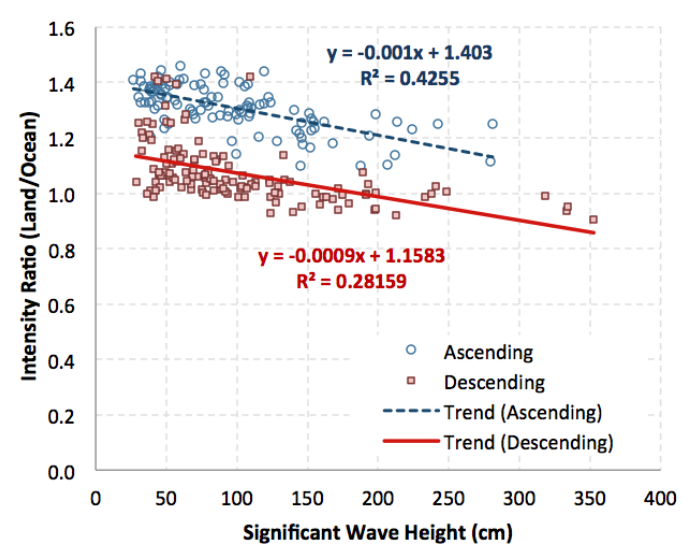

Figure 9. Intensity ratio of ascending and descending images with respect to wave height.

Wave height also appears to be correlated with the intensity ratio (Figure 9). For both the ascending and descending images, the intensity ratio decreases with increasing wave height. The next section presents data that shows that larger wave heights often result in higher errors. This may be partly caused by this decrease in intensity ratio, which makes it harder to distinguish land from water. Finally, though fewer of the descending images were classified as "Good" or "Acceptable," their median horizontal error was about $2 / 3$ that of the ascending images (Table 2). The reason for this is unknown, and should be investigated further.

\subsection{Influence of Environmental Conditions on Shoreline Accuracy}

SAR intensity depends on a number of factors related to the ground location such as roughness, shape, orientation, and moisture content. Very smooth surfaces, like water, tend to have relatively low intensity. Soil with higher moisture content tends to have higher intensity, due to large differences in electrical properties between water and air [44]. Furthermore, motion at the surface in the across-track direction of the satellite causes a shift of that particular surface element in the image in the along-track direction [45]. Since the effective velocity of the water surface due to waves and tides is spatially variable, a range of along-track shifts can be expected, causing a blurring effect in the image, depending on the movement of the water. In order to investigate the effect of environmental conditions on shoreline accuracy, climate and wave parameters (Section 2.2.3) are calculated for each SAR image using the date and time of SAR image acquisition. This makes it possible to check for correlations between various environmental conditions and the level of error of the shoreline detections (calculated as described in Section 3.2). Wave height, wind speed, and cumulative rainfall three days prior to image collection are all considered in this analysis. High wave conditions are expected to affect the roughness of the water surface, possibly increasing the pixel intensity (especially in a broader surf zone). Similarly, high wind conditions tend to roughen the water surface, causing white capping. Cumulative rainfall is selected as an indicator of soil moisture. Time offset between SAR image and survey are also tested to see if this had a detectable effect on the error.

As explained in Section 3.3, only the ascending images are considered in this analysis. Additionally, only shoreline detections that are classified as "Good" and "Acceptable" (Section 3.1) are considered. This removes the outliers, which are primarily a result of defective images or poor detections, and focuses on identifying the causes of more subtle differences between successful detections. Finally, seven additional images were excluded because they were collected between April and June 2011, before topographic survey data was available. After these screening criteria are applied, a total of 55 images remain for consideration in this analysis.

Wave height shows a strong positive correlation with error $\left(R=0.88, p\right.$-value $=1.0 \times 10^{-12}$, Figure 10a). Wind speed showed a weaker positive correlation $\left(R=0.53, p\right.$-value $=2.8 \times 10^{-5}$, Figure 10b). This correlation is likely due to the fact that waves in the North Sea are generally wind-driven, and it 
is likely that strong winds coincide with large waves [46]. Similarly, rainfall had a weak positive correlation $(R=0.31, p$-value $=0.023$, Figure 10c), but the correlation is skewed by a few large rainfall days, which all coincide with high wave events. The time offset between the topographic survey and the SAR image showed no correlation with error $(R=0.00)$. As the time offset increases (and the Sand Motor therefore has more time to evolve), it is expected that the survey- and SAR-derived shorelines become increasingly different, resulting in a higher "error". However, the average offset is 15 days, and morphological activity is likely to be small over such timeframes. An average rate of change of $\sim 100 \mathrm{~m}$ /year, as was observed in the topographic surveys (Figure 8), this corresponds to an average $\sim 4 \mathrm{~m}$ error due to the time offset, which is $7 \%-10 \%$ of the errors reported in Table 2.

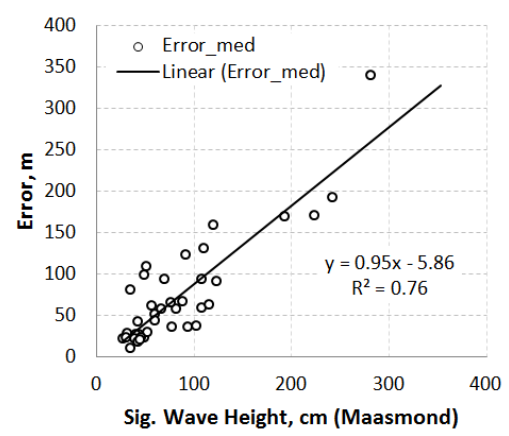

(a)

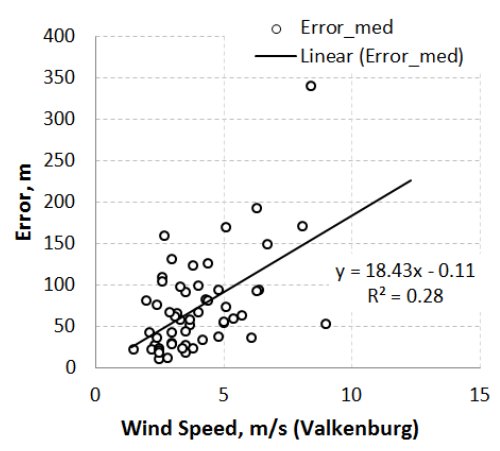

(b)

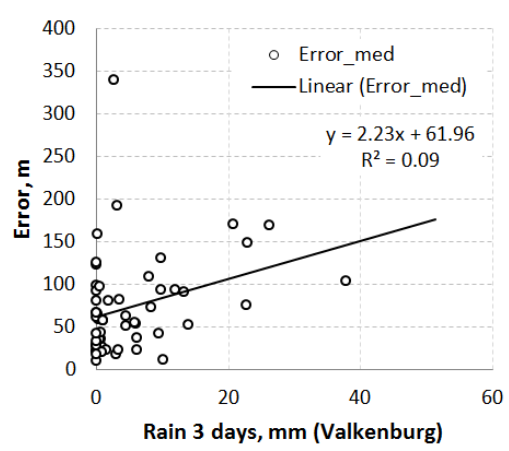

(c)

Figure 10. Horizontal error in shoreline estimates as function of (a) significant wave height at a nearby offshore platform and (b) wind speed and (c) rainfall at the nearest weather station for the ascending TerraSAR-X dataset. Linear regression model parameters are displayed in the graph.

Since images taken during high wave conditions generally correspond to large error, it may be necessary to set an upper limit on wave height for images to be considered. In our study however, only four images were collected with high (e.g., $>150 \mathrm{~cm}$ ) significant wave height. Therefore, we decided not to implement such a threshold. In summary, the results based on ascending data show that shorelines on beaches can be derived from TerraSAR-X satellite data with a median horizontal error of $58 \mathrm{~m}$, when incorporating both good and acceptable shorelines (78\% of total number of images). When including the limited number of good and acceptable shorelines that could be detected from descending data ( $37 \%$ of total), this number improves to $51 \mathrm{~m}$ ( $55 \%$ of total ascending and descending images).

\section{Discussion}

\subsection{Applications of Shorelines from TerraSAR-X Images}

The presented technique provides the benefits of satellite remote sensing for shoreline extraction (global coverage, low acquisition costs), yet the accuracy obtained (10s of $\mathrm{m}$ ) is relatively low compared to the TerraSAR-X pixel size of $3 \mathrm{~m}$. This accuracy makes the TerraSAR-X data less favorable for short timescales or single observations. The location of the shoreline varies on short timescales due to varying tide and local wind and wave setup, which complicates the definition of a single shoreline location on a daily timescale. In addition, water movement in the along-track direction negatively affects the accuracy of the extracted shorelines. However, at locations with larger natural dynamics or with large human interventions in the coastal system, the shoreline variations exceed the positional accuracy of shorelines derived from TerraSAR-X. At such locations (e.g., river delta degradation [47], large sand nourishments [34], beaches downdrift of large harbor breakwaters [48] and spit formations [49]), shoreline changes can easily be $\sim 50 \mathrm{~m}$ over a period of month(s). For long-term, large-scale monitoring of these sites, the proposed method with the shown accuracy of $\sim 50 \mathrm{~m}$ could present a good alternative. 


\subsection{Availability of SAR Imagery}

To reach the accuracy level of tens of meters, as achieved in this study, ideally very high-resolution SAR data should be used, such as the $3 \times 3 \mathrm{~m}$ resolution data applied here. This data is currently only available via (semi-)commercial satellite missions, such as the TerraSAR-X, Cosmo-SkyMed, and RadarSAT-2 satellites. These systems have two main advantages. First, the data can be acquired under a large range of incidence angles, hence acquisitions with large incidence angles can be used for optimal land-sea classification. Second, the repeat cycle, and thereby the revisit cycle, of the satellites is relatively short. The revisit time is, for example, 11 days for the TerraSAR-X mission and as little as four days for the Cosmo-SkyMed satellites. A disadvantage of these missions is that, in general, the satellites do not acquire data unless there is a customer for the particular area. This means that the historic data archive is relatively small, and only new acquisitions can be used for the analysis. Moreover, the spatial extent of high-resolution SAR imagery is limited $(30 \times 50 \mathrm{~km}$ for the TerraSAR-X StripMap mode used here). Hence, the area that can be monitored by a single image is relatively small. Another large disadvantage of using the commercial data is the acquisition cost. Therefore, we intend to assess the performance of the freely available Sentinel-1 data in a follow-up study. With a nominal repeat cycle of six days, the temporal sampling of the data is favorable. The ground range resolution of Sentinel-1 is $5 \mathrm{~m}$, approaching the high-resolution data, whereas the resolution in azimuth direction is in the order of $20 \mathrm{~m}$. Therefore, the performance will be dependent on the orientation of the coastline.

\subsection{Method Improvement}

The resulting accuracy of the extracted shorelines, on the order of $10 \mathrm{~s}$ of meters, is rather coarse. This is a result of several factors: the characteristics of SAR imaging including speckle and blurring due to water surface motion, uncertainties in the validation process, and inaccuracies in the SAR shoreline extraction and georeferencing. In the validation process, interpolated water levels and RTK-GPS elevation profiles are used to derive a shoreline at the time of the SAR acquisitions. As indicated in Section 2.3.5, for a beach with a slope of 1:50, an error in the water level of $50 \mathrm{~cm}$ leads to a shoreline error of $25 \mathrm{~m}$. Furthermore, the instantaneous effect of an incoming wave on the land-water boundary, which does not affect the GPS-derived shoreline, directly affects the comparison. Therefore, the accuracies reported here are reasonable in light of the potential contributors to uncertainty.

Nevertheless, some improvements in the georeferencing and extraction procedure are possible. The actual extraction is based on stacks of co-registered SAR images. This co-registration results in an intrinsic accuracy within the image domain at sub-meter level. However, the transformation to geographical coordinates, which is based here on ground control points, causes a reduction of the precision in the final product, which is compared to the in-situ measurements. To improve positioning in future work, a satellite orbit and Digital Elevation Model (DEM)-based geolocalization procedure will be evaluated, in combination with a radar corner reflector/transponder with Global Navigation Satellite System (GNSS)-measured location to remove orbit and timing errors [50]. Alternatively, the performance when using the annotated geolocalization parameters in the Terra-SAR-X products should be evaluated. Indeed, a comparison of results as obtained by the workflow used in this paper compared to results obtained directly from the annotated geolocalization parameters could possibly reveal systematic shifts that then could be attributed to the described co-registration procedure. Also, in DEM-based geolocation, the choice of DEM, global or nation-wide, could have some effect in the final geolocation quality.

Sea state and image acquisition configuration appears to have a strong influence on the accuracy of the identified shorelines. As a consequence, not all shorelines have sufficient accuracy to contribute to the ultimate goal of this technique: the monitoring of coastline evolution. Therefore, we chose to manually evaluate automatically-identified shorelines and reject them if necessary. This manual step, which is both subjective and time consuming, should be automated. One approach would be to first apply a line-smoothing step on the estimated shorelines [51], followed by an automatic evaluation of the distances of the estimated shoreline to the smoothed shoreline. Shorelines with 
larger distances from their smoothed counterpart would be rejected, while in the remaining cases, the smoother shoreline could possibly replace the initial estimate.

In this paper, k-means clustering was used as a first step in automatically obtaining SAR pixels representing sea and land. Alternative unsupervised and supervised classification methods may provide better results [52]. Methods that have been applied successfully to the clustering of SAR pixels include Kohonen Self Organizing Maps [53], Mean-Shift [54], and iterative region growing [55]. Notably, reference [56] studies variations in statistical feature values between land cover classes derived from an ERS SAR image of an overlapping area.

\subsection{Comparison to Extracted Shorelines of Others}

The potential accuracy of shorelines derived from satellite imagery depends on several factors, including sensor characteristics and pixel size, sensor acquisition geometry, shoreline characteristics, sea state, and processing methodology. This makes it challenging to directly compare the accuracy of results as obtained in different studies [57]. A better way to compare processing methods would be for different teams to process the same input data. Compared to our results, Bruno et al. 2016 [58] report a higher mapping accuracy $(\sim 2 \mathrm{~m})$ for shoreline extraction in the Apulia region (Italy) from X-band SAR images from the COSMO-SkyMed constellation. A recent study [59] that used TerraSAR-X in the German Wadden Sea did not quantify accuracy, but their results seem comparable to ours.

\section{Conclusions}

Mapping shoreline change for long stretches of coast and long time periods is potentially costly and labor-intensive. We examined the applicability of an alternative method to detect shoreline change using satellite SAR images (TerraSAR-X). An extensive and complete dataset of nearly 200 SAR satellite images was analyzed to assess the errors in shorelines obtained for a four kilometer stretch of coast containing a mega-scale beach nourishment. A semi-automated workflow was used to classify the images and find the land-water interface.

From the group of SAR images with a relatively shallow incidence angle of $39^{\circ}, 78 \%$ of the acquired images were suitable for the extraction of a shoreline. For a steeper incidence angle, this percentage dropped to $37 \%$. Hence, a proper selection of the imaging configuration is required to optimize the success rate of SAR-based shoreline extraction.

Our results show that the error between the SAR-derived shorelines and the in-situ RTK-GPS shorelines was, on average, $51 \mathrm{~m}$. Moreover, the accuracy is dependent on the environmental conditions. Days with large waves near the coast result in a blurred transition between land and water and therefore higher error. Rainfall and temperature only had a minor correlation with the accuracy.

The increasing resolution of SAR images, combined with rapid and large-scale changes at mega-nourishments, make it possible to detect shoreline changes using SAR images. The accuracy obtained in this study $(\sim 50 \mathrm{~m})$ is, in most cases, insufficient for monitoring minor changes along natural beaches. For expansive study areas experiencing rapid/large-scale changes, however, such as mega-scale beach nourishments or dynamic barrier island systems, such as those in the Dutch and German Wadden Sea, an SAR-derived shoreline mapping technique can provide an efficient solution with high temporal resolution, which thereby contributes to the increasing portfolio of remote sensing coastal observation methods [60].

Acknowledgments: Elena Vandebroek was supported by the Netherlands America Foundation and the Fulbright U.S. Student Program. Matthieu de Schipper and Sierd de Vries were supported by the ERC-Advanced Grant 291206-NEMO. Bathymetric surveys were commissioned by the Dutch Ministry of Infrastructure and the Environment (Rijkswaterstaat) with the support of the Province of South-Holland, the European Fund for Regional Development (EFRO), and EcoShape/Building with Nature. The Building with Nature program (2008-2012) received funding from the Dutch Ministry of Transport, Public Works and Water Management, the municipality of Dordrecht, EFRO, as well as the participants of the EcoShape Foundation. The TerraSAR-X data is provided by the German Aerospace Center (DLR) within the framework of projects MTH0246 and MTH1293. Tide and wave data were obtained from the Ministry of Public Works and the Environment. Climate data was obtained from the 
Royal Netherlands Meteorological Institute KNMI. Finally, we would like to thank the four anonymous reviewers whose comments helped improve and clarify this manuscript.

Author Contributions: E.V., R.L., F.v.L., M.d.S. and S.d.V. wrote the paper. E.V. analyzed the data; all authors contributed to conceiving and designing the experiments and reviewing the paper.

Conflicts of Interest: The authors declare no conflict of interest. The founding sponsors had no role in the design of the study; in the collection, analyses, or interpretation of data; in the writing of the manuscript, and in the decision to publish the results.

\section{References}

1. Gens, R. Remote sensing of coastlines: Detection, extraction and monitoring. Int. J. Remote Sens. 2010, 31, 1819-1836. [CrossRef]

2. Kroon, A.; Davidson, M.A.; Aarninkhof, S.G.J.; Archetti, R.; Armaroli, C.; Gonzalez, M.; Medri, S.; Osorio, A.; Aagaard, T.; Holman, R.A.; et al. Application of remote sensing video systems to coastline management problems. Coast. Eng. 2007, 54, 493-505. [CrossRef]

3. Boak, E.H.; Turner, I.L. Shoreline definition and detection: A review. J. Coast. Res. 2005, 21, 688-703. [CrossRef]

4. Holman, R.A.; Stanley, J. The history and technical capabilities of Argus. Coast. Eng. 2007, 54, 477-491. [CrossRef]

5. Armaroli, C.; Ciavola, P.; Balouin, Y.; Gatti, M. An integrated study of shoreline variability using GIS and ARGUS techniques. J. Coast. Res. 2004, 39, 34-52.

6. Elko, N.A.; Holman, R.A.; Gelfenbaum, G. Quantifying the rapid evolution of a nourishment project with video imagery. J. Coast. Res. 2005, 21, 633-645. [CrossRef]

7. Harley, M.D.; Andriolo, U.; Armaroli, C.; Ciavola, P. Shoreline rotation and response to nourishment of a gravel embayed beach using a low-cost video monitoring technique: San Michele-Sassi Neri, Central Italy. J. Coast. Conserv. 2014, 18, 551-565. [CrossRef]

8. Klemas, V. Airborne remote sensing of coastal features and processes: An overview. J. Coast. Res. 2012, 29, 239-255. [CrossRef]

9. Klemas, V. Coastal and Environmental Remote Sensing from Unmanned Aerial Vehicles: An Overview. J. Coast. Res. 2015, 31, 1260-1267. [CrossRef]

10. Mills, J.P.; Buckley, S.J.; Mitchell, H.L.; Clarke, P.J.; Edwards, S.J. A geomatics data integration technique for coastal change monitoring. Earth Surf. Process. Landf. 2005, 30, 651-664. [CrossRef]

11. Lindenbergh, R.C.; Hanssen, R. Eolian deformation detection and modeling using airborne laser altimetry. In Proceedings of the 2003 IEEE International Geoscience and Remote Sensing Symposium, Toulouse, France, 21-15 July 2003; pp. 1-4.

12. Gares, P.A.; Wang, Y.; White, S.A. Using LIDAR to monitor a beach nourishment project at Wrightsville Beach, North Carolina, USA. J. Coast. Res. 2006, 22, 1206-1219. [CrossRef]

13. Stockdon, H.F.; Sallenger, A.H., Jr.; List, J.H.; Holman, R.A. Estimation of shoreline position and change using airborne topographic lidar data. J. Coast. Res. 2002, 19, 502-513.

14. Smeeckaert, J.; Mallet, C.; David, N.; Chehata, N.; Ferraz, A. Large-scale classification of water areas using airborne topographic lidar data. Remote Sens. Environ. 2013, 138, 134-148. [CrossRef]

15. Ryu, J.H.; Won, J.S.; Min, K.D. Waterline extraction from Landsat TM data in a tidal flat: A case study in Gomso Bay, Korea. Remote Sens. Environ. 2002, 83, 442-456. [CrossRef]

16. Pardo-Pascual, J.E.; Almonacid-Caballer, P.; Ruiz, L.A.; Palomar-Vázquez, J. Automatic extraction of shorelines from Landsat TM and ETM+ multi-temporal images with subpixel precision. Remote Sens. Environ. 2012, 123, 1-11. [CrossRef]

17. Maiti, S.; Bhattacharya, A.K. Shoreline change analysis and its application to prediction: A remote sensing and statistics based approach. Mar. Geol. 2009, 257, 11-23. [CrossRef]

18. Guariglia, A.; Buonamassa, A.; Losurdo, A.; Saladino, R.; Trivigno, M.L.; Zaccagnino, A.; Colangelo, A. A multisource approach for coastline mapping and identification of shoreline changes. Ann. Geophys. 2006, 49, 295-304.

19. Horritt, M.S.; Mason, D.C.; Luckman, A.J. Flood boundary delineation from synthetic aperture radar imagery using a statistical active contour model. Int. J. Remote Sens. 2001, 22, 2489-2507. [CrossRef] 
20. Strozzi, T.; Wiesmann, A.; Kääb, A.; Joshi, S.; Mool, P. Glacial lake mapping with very high resolution satellite SAR data. Nat. Hazards Earth Syst. Sci. 2012, 12, 2487. [CrossRef]

21. Lee, J.S.; Jurkevich, I. Coastline detection and tracing in SAR images. IEEE Trans. Geosci. Remote Sens. 1990, $28,662-668$.

22. Li, Z.; Heygster, G.; Notholt, J. Intertidal topographic maps and morphological changes in the German Wadden Sea between 1996-1999 and 2006-2009 from the waterline method and SAR images. IEEE J. Sel. Top. Appl. Earth Obs. Remote Sens. 2014, 7, 3210-3224. [CrossRef]

23. Martinis, S.; Twele, A.; Voigt, S. Towards operational near real-time flood detection using a split-based automatic thresholding procedure on high resolution TerraSAR-X data. Nat. Hazards Earth Syst. Sci. 2009, 9, 303-314. [CrossRef]

24. Martinis, S.; Twele, A. A hierarchical spatio-temporal Markov model for improved flood mapping using multi-temporal X-band SAR data. Remote Sens. 2010, 2, 2240-2258. [CrossRef]

25. Krijger, J.M.; Weele, M.V.; Aben, I.; Frey, R. Technical Note: The effect of sensor resolution on the number of cloud-free observations from space. Atmos. Chem. Phys. 2007, 7, 2881-2891. [CrossRef]

26. Heygster, G.; Dannenberg, J.; Notholt, J. Topographic mapping of the German tidal flats analyzing SAR images with the waterline method. IEEE Trans. Geosci. Remote Sens. 2009, 48, 1019-1030. [CrossRef]

27. Mason, D.C.; Davenport, I.J.; Flather, R.A.; Gurney, C.; Robinson, G.J.; Smith, J.A. A sensitivity analysis of the waterline method of constructing a digital elevation model for intertidal areas in ERS SAR scene of Eastern England. Estuar. Coast. Shelf Sci. 2001, 53, 759-778. [CrossRef]

28. Kim, D.J.; Moon, W.M.; Park, S.E.; Kim, J.E.; Lee, H.S. Dependence of waterline mapping on radar frequency used for SAR images in intertidal areas. IEEE Geosci. Remote Sens. Lett. 2007, 4, 269-273. [CrossRef]

29. Rijkswaterstaat. Land/Water Detection with Polarimetric SAR; Rijkswaterstaat rapportnr; AGI-2006-GAB-027; Rijkswaterstaat Adviesdienst Geo-informatie en ICT: Delft, The Netherlands, 2006.

30. Robinson, D.A.G.; Bijker, W.; Tolpekin, V.A. Shoreline Detection Using TerraSAR-X Quad Polarization Mode. Int. Hydrogr. Rev. 2015, 10, 15-25.

31. Short, A.D. Beach systems of the central Netherlands coast: Processes, morphology and structural impacts in a storm driven multi-bar system. Mar. Geosci. 1992, 107, 103-137. [CrossRef]

32. Wijnberg, K.M. Environmental controls on decadal morphologic behaviour of the Holland coast. Mar. Geosci. 2002, 189, 227-247. [CrossRef]

33. Stive, M.J.F.; de Schipper, M.A.; Luijendijk, A.P.; Aarninkhof, S.G.J.; van Gelder-Maas, C.; van Thiel de Vries, J.S.M.; de Vries, S.; Henriquez, M.; Marx, S.; Ranasinghe, R. A new alternative to saving our beaches from local sea-level rise: The Sand Engine. J. Coast. Res. 2013, 29, 1001-1008. [CrossRef]

34. De Schipper, M.A.; de Vries, S.; Ruessink, B.G.; De Zeeuw, R.C.; Rutten, J.; van Gelder-Maas, C.; Stive, M.J.F. Initial spreading of a mega feeder nourishment: Observations from the Sand Engine pilot project. Coast. Eng. 2016, 111, 23-38. [CrossRef]

35. Kampes, B.M.; Hanssen, R.F.; Perski, Z. Radar interferometry with public domain tools. In Proceedings of the Third International Workshop on ERS SAR Interferometry, 'FRINGE03', Frascati, Italy, 1-5 December 2003.

36. Ketelaar, V.B.H. Satellite Radar Interferometry: Subsidence Monitoring Techniques, 1st ed.; Springer: Dordrecht, The Netherlands, 2009.

37. Qui, F.; Berglund, J.; Jensen, J.R.; Thakkar, P.; Ren, D. Speckle noise reduction in SAR imagery using a local adaptive median filter. GISci Remote Sens. 2004, 41, 244-266.

38. Patidar, P.; Gupta, M.; Srivastava, S.; Nagawat, A.K. Image de-noising by various filters for different noise. Int. J. Comput. Appl. 2010, 9, 45-50. [CrossRef]

39. Jain, A.K. Data clustering: 50 years beyond K-means. Pattern Recogn. Lett. 2010, 31, 651-666. [CrossRef]

40. MacQueen, J. Some methods for classification and analysis of multivariate observations. In Proceedings of the Fifth Berkeley Symposium on Mathematical Statistics and Probability Volume 1: Statistics, Berkeley, CA, USA, 21 June-18 July 1967.

41. Brown, L. A Survey of Image Registration Techniques. ACM Comput. Surv. 1992, 24, 325-376. [CrossRef]

42. Ulaby, F.T.; Moore, R.K.; Fung, A.K. Volume 1, Microwave Remote Sensing Fundamentals and Radiometry. In Microwave Remote Sensing Active and Passive; Artech House: Norwood, UK, 1982.

43. Bosboom, J.; Stive, M. Coastal Dynamics 1; Delft Academic Press: Delft, The Netherlands, 2015.

44. Massonnet, D.; Souyris, J.-C. Imaging with Synthetic Aperture Radar; EPFL Press: Lausanne, Switzerland, 2008. 
45. Raney, R.K. Synthetic Aperture Imaging Radar and Moving Targets. IEEE Trans. Aerosp. Electron. Syst. 1971, 7, 499-505. [CrossRef]

46. Vikebø, F.; Furevik, T.; Furnes, G.; Kvamstø, N.G.; Reistad, M. Wave height variations in the North Sea and on the Norwegian Continental Shelf, 1881-1999. Cont. Shelf Res. 2003, 23, 251-263. [CrossRef]

47. Coleman, J.M. Dynamic changes and processes in the Mississippi River delta. Geol. Soc. Am. Bull. 1988, 100, 999-1015. [CrossRef]

48. Hsu, J.R.; Uda, T.; Silvester, R. Beaches downcoast of harbours in bays. Coast. Eng. 1993, 19, $163-181$. [CrossRef]

49. Dan, S.; Walstra, D.J.R.; Stive, M.J.; Panin, N. Processes controlling the development of a river mouth spit. Mar. Geol. 2011, 280, 116-129. [CrossRef]

50. Mahapatra, P.S.; Samiei-Esfahany, S.; van der Marel, H.; Hanssen, R.F. On the Use of Transponders as Coherent Radar Targets for SAR Interferometry. IEEE Trans. Geosci. Remote Sens. 2014, 52, 1869-1878. [CrossRef]

51. Burghardt, D. Controlled Line Smoothing by Snakes. GeoInformatica 2005, 9, 237-252. [CrossRef]

52. Bishop, C.M. Pattern and Machine Learning; Springer Science+Business Media, LLC: New York, NY, USA, 2006.

53. Karvonen, J.A. Baltic sea ice SAR segmentation and classification using modified pulse-coupled neural networks. IEEE Trans. Geosci. Remote Sens. 2004, 42, 1566-1574. [CrossRef]

54. Jarabo-Amores, P.; Rosa-Zurera, M.; de la Mata-Moya, D.; Vicen-Bueno, R.; Maldonado-Bascon, S. Spatial-range mean-shift filtering and segmentation applied to SAR images. IEEE Trans. Instrum. Meas. 2011, 60, 584-597. [CrossRef]

55. Yu, Q.; Clausi, D.A. SAR sea-ice image analysis based on iterative region growing using semantics. IEEE Trans. Geosci. Remote Sens. 2007, 45, 3919-3931. [CrossRef]

56. Dekker, R.J. Texture analysis and classification of ERS SAR images for map updating of urban areas in the Netherlands. IEEE Trans. Geosci. Remote Sens. 2003, 41, 1950-1958. [CrossRef]

57. Mitra, D.; Basu, A. Performance testing of selected automated coastline detection techniques applied on multispectral satellite imageries. Earth Sci. Inform. 2017, 1-10. [CrossRef]

58. Bruno, M.F.; Molfetta, M.G.; Mossa, M.; Nutricato, R.; Morea, A.; Chiaradia, M.T. Coastal observation through Cosmo-SkyMed high-resolution SAR images. In Proceedings of the 14th International Coastal Symposium, Sydney, Australia, 6-11 March 2016.

59. Wiehle, S.; Lehner, S. Automated Waterline Detection in the Wadden Sea Using High Resolution TerraSAR-X Images. J. Sens. 2015, 2015. [CrossRef]

60. Liu, Y.; Kerkering, H. Coastal Ocean Observing Systems; Elsevier (Academic Press): London, UK, 2015. 